https://dx.doi.org/10.4314/ijs.v19i2.3

Ife Journal of Science vol. 19, no. 2 (2017)

\title{
OPTIMIZATION OF EXTRACTION OF MICROCRYSTALLINE CELLULOSE FROM ORANGE PEEL WASTE USING RESPONSE SURFACE METHODOLOGY
}

\author{
Akhabue C. E and Osubor N. T. \\ Department of Chemical Engineering, Faculty of Engineering, University of Benin, Benin City, Nigeria \\ *Corresponding Author: christopher.akhabue@uniben.edu Tel: +234-8033553215 \\ (Received: $9^{\text {th }}$ March, 2017; Accepted: $13^{\text {th }}$ August, 2017)
}

ABSTRACT

\begin{abstract}
This study investigated the optimum processing conditions for obtaining the maximum yield of microcrystalline cellulose (MCC) powder from orange peel waste (OPW) by use of response surface methodology (RSM). Central composite design (CCD) was used to evaluate the optimum process conditions for producing MCC from alpha cellulose obtained from OPW. The factors investigated for getting the optimum conditions were temperature $\left(90-110^{\circ} \mathrm{C}\right)$ and hydrolysis time $(10-25 \mathrm{~min})$. Both factors were found to have significant effect on the yield of MCC and the model that described the process had coefficient of determination $\left(\mathrm{R}^{2}\right)$ of 0.9808 . The adjusted $\mathrm{R}^{2}$ was checked to ensure model adequacy, which gave a value of 0.9695 . Optimum process conditions for hydrolysis as ascertained by RSM were $100.53{ }^{\circ} \mathrm{C}$ and $16.28 \mathrm{~min}$. Characterization of the optimized MCC obtained showed that it had an angle of repose of $50.08^{\circ}, \mathrm{pH}$ of 6.7 , moisture content of $6 \%$ bulk and true density of 0.346 and $1.48 \mathrm{~g} / \mathrm{ml}$ respectively indicating a similar degree of crystallinity as that of commercial grade microcrystalline cellulose (Avicel PH101). It was however found to be composed of aggregated fibres at magnifications of $1000 \mathrm{X}$ using a scanning electron microscopy (SEM) as opposed to the non-aggregated fibres of Avicel PH101 at same magnification.
\end{abstract}

Keywords: Microcrystalline cellulose, Orange peel waste, Alpha cellulose, Response surface methodology

\section{INTRODUCTION}

The orange, specifically sweet orange (Citrus sinensis) is one of the most cultivated fruit trees in the world (Morton, 1987). They are widely grown in the tropical and subtropical climatic regions of the world. The fruit of the orange tree has an edible endocarp and can be eaten fresh or processed for its juice, while its outer pericarp (peel) or flavedo as it is termed for the citrus family is in most cases discarded. However, this part that is normally discarded contains the agent responsible for its fragrance which can be gotten by the extraction of the oil from its peel. The orange peel also contains significant amount of vitamin $\mathrm{C}$, limonene, cellulose, hemicelluloses and lignin (Barros et al., 2012). Cellulose is the most abundant organic polymer on earth (Klemm et al. 2005). It is an important structural component of the primary cell wall of green plants. Aside from being the primary building material in plants, cellulose has many other uses. Depending on its treatment, cellulose can be used to make paper, film, explosives and plastics, in addition to many other industrial uses. Cellulose for industrial application is mainly obtained from wood pulp and cotton, with both having a cellulose content of about $40-50$ and $90 \%$ respectively (Klemm et al. 2005).
One of the many industrial applications of cellulose is its use in the production of microcrystalline cellulose (MCC). MCC, which is also known as refined wood pulp, is cellulose obtained after successful separation of cellulose micro-fibril from its amorphous regions and is gotten from wood pulp and cotton linters (Klemm et al. 2005). MCC is one of the most important tableting excipients thanks to its outstanding dry binding properties, enabling the manufacture of tablets by direct compression (Achor et al., 2014). It has a wide range of uses, it can be used as an anti-caking agent, as a fat substitute and it is approved within the European Union as a thickener and emulsifiers (Klemm et al. 2005).

As earlier stated MCC for the purpose of industrial production is usually obtained from wood pulp and purified cotton linters (Evans et al., 1989). Cotton is a high value added crop whilst wood pulp originates from some manner of deforestation. With increasing awareness of global deforestation issues, more efforts are being put into the production of more environmentally friendly products that utilize less environmental resources, reduces the emission of pollutants to the environment and also serve as substitute for 
more valuable resources. The need for a more environmentally friendly starting material as well as the need to slow down the fast global deforestation has led to the utilization of waste materials for the production of valuable materials. The production of MCC from wood pulp has stimulated renewed interest in agro plant wastes (Moore, 1996). MCC obtained from cotton linters is, economically speaking, unreasonable, since MCC has a lower market value compared to cotton.

The aim of this present study was to optimize the production of MCC from orange peel waste (OPW) using response surface methodology (RSM). This study uses RSM to provide optimized conditions for the maximum yield of MCC from OPW. RSM combines mathematical and statistical analyses of observed or experimental results that is used to establish an empirical relationship between variables and the desired responses. It also provides a complete experimental design for data exploration, model fitting as well as process optimization (Karim et al., 2014).

\section{METHODOLOGY \\ Materials and Chemicals}

Oranges were purchased from New Benin Market, Benin City, Edo State, Nigeria. The following chemicals: hydrochloric acid, sodium hydroxide pellets, xylene, sodium hypochlorite stock solution and sodium sulfite crystals were purchased from Pyrex - IG Scientific Company in Benin City, Edo State. The chemicals were of analytical grade.

\section{Preparation of Feedstock}

The oranges were peeled with a laboratory knife. The peels were then sundried for $48 \mathrm{~h}$ to reduce the moisture content, further oven dried at $100{ }^{\circ} \mathrm{C}$ and periodically weighed, until an approximately constant weight of sample was obtained. The dried peels were then milled with the help of a milling machine and passed through a series of stacked standard sieves (1.8, 2.5 and $3.0 \mathrm{~mm})$. Powdered peels of approximately $2.5 \mathrm{~mm}$ particle size were then collected for further analysis.

\section{Extraction of Alpha Cellulose}

The extraction of alpha cellulose was conducted by employing the method used by Okhamafe and Azubuike (1994) with slight modifications. Briefly milled samples weighing $75 \mathrm{~g}$ were delignified by mixing with $1 \mathrm{~L}$ of $2 \mathrm{M} \mathrm{NaOH}$ solution and heated to $121{ }^{\circ} \mathrm{C}$ for an hour and then washed thoroughly and filtered using a domestic sieve of small mesh size. The filtered sample was then digested in $750 \mathrm{ml}$ of $3 \% \mathrm{w} / \mathrm{v}$ each of sodium sulfite and sodium hydroxide solution at a temperature of $60^{\circ} \mathrm{C}$ for an hour. The mixture was further washed and filtered several times until the soapy feel of the sample was no longer felt. Thereafter, the sample was bleached with aqueous dilution of $3.5 \% \mathrm{w} / \mathrm{v}$ sodium hypochlorite solution of equal weight with the sample at boiling temperature for $10 \mathrm{~min}$ and then washed and filtered. The sample was then treated with $500 \mathrm{ml}$ of $17.5 \% \mathrm{w} / \mathrm{v}$ of sodium hydroxide solution at 80 ${ }^{\circ} \mathrm{C}$ for $30 \mathrm{~min}$. The resulting alpha cellulose was then thoroughly washed and filtered using a sieve and further bleached with aqueous dilution of $3.5 \% \mathrm{w} / \mathrm{v}$ sodium hypochlorite for $5 \mathrm{~min}$ at $100^{\circ} \mathrm{C}$ and then washed and filtered and manually squeezed to obtain small lumps which were sun dried for $5 \mathrm{~h}$.

\section{Experimental Design}

The alpha cellulose obtained was weighed and $8 \mathrm{~g}$ of it was collected and hydrolyzed using $40 \mathrm{ml}$ of 2.5 M hydrochloric acid. In this study, response surface methodology (RSM) was used to estimate the optimum values of the independent variables (temperature and hydrolysis time) to obtain the maximum response (MCC yield (\%)).

The coded and actual levels of the two independent variables are listed in table 1 . The experimental design for the extraction was carried out using a central composite design (CCD). A total of 13 experimental runs were designed by the CCD consisting of four factorial, four axial and five center points. 
Table 1. Coded and actual levels for the two independent variables in the CCD

\begin{tabular}{|c|c|c|c|c|c|c|}
\hline \multirow[t]{2}{*}{ Variable } & \multirow[t]{2}{*}{ Symbol } & \multicolumn{5}{|c|}{ Range and their levels } \\
\hline & & -1.414 & 1 & 0 & 1 & 1.414 \\
\hline $\begin{array}{l}\text { Temperature } \\
\left({ }^{\circ} \mathrm{C}\right) \\
\text { Hydrolysis }\end{array}$ & 1 & 90 & 92.93 & 100 & 107.07 & 110 \\
\hline Time (min) & 2 & 10 & 12.2 & 17.50 & 22.80 & 25.0 \\
\hline
\end{tabular}

After each run, the reaction was halted by adding a 10 -fold excess cold water and stirred vigorously to neutralize the acid and the solution poured through a $500 \mu \mathrm{m}$ sieve and the filtrate allowed to stand overnight. The filtrate was first decanted and then passed through a Whatmann filter paper $(11 \mathrm{~cm})$ to enable further separation. The MCC residue obtained on the Whatmann paper was then collected and stored in a refrigerator at a temperature at $4{ }^{\circ} \mathrm{C}$. The yield was calculated using Eq. 1.

MCC yield $=\frac{\text { mass of microcrystalline cellulose obtained }}{\text { mass of alpha cellulose used }} \times 100$

\section{Statistical Analysis}

The experimental data obtained from the use of the CCD were analyzed by RSM using the second order polynomial equation to describe the relationship between the predicted response variable (MCC yield) and the independent variables of the process. The regression coefficient of the second order multiple regression model was determined using the data obtained from the CCD employed for the optimization of the hydrolysis variables as shown in Eq. 2

$Y_{\text {yield }}=b_{0}+\sum_{i=1}^{n} b_{i} X_{i}+\sum_{i=1}^{n} b_{i i} X_{i}^{2}+\sum_{i i>j}^{n} \sum_{j}^{n} b_{i j} X_{i} X_{j}+e$

Where $Y_{\text {yield }}$ is the predicted response (MCC yield), $\mathrm{b}_{\mathrm{o}}, \mathrm{b}_{\mathrm{i}}, \mathrm{b}_{\mathrm{ij}}, \mathrm{b}_{\mathrm{ij}}$ are intercept, linear, quadratic and interaction constant coefficient respectively, $\mathrm{n}$ is the number of independent variables studied and optimized in the experimental work. $\mathrm{X}_{\mathrm{i}}, \mathrm{X}_{\mathrm{j}}$ are the actual independent variables and $\mathrm{e}$ is the error term. The RSM was applied to the experimental data using a commercial statistical package, Design Expert version 7.0.0 (Stat-ease Inc., Minneapolis). The experiments were carried out in a random order to minimize effects of explained variability in the observed responses due to extraneous factors. Coefficient of determination $\left(\mathrm{R}^{2}\right)$ and analysis of variance (ANOVA) were used to evaluate the quality of the model. The mathematical model was only considered satisfactory when the ANOVA data showed a high level of statistical significance.

\section{Characterization of Microcrystalline Cellulose}

The MCC samples obtained from the OPW were characterized. The $\mathrm{pH}$ of the MCC was determined by shaking $2 \mathrm{~g}$ of it with $100 \mathrm{ml}$ distilled water for $5 \mathrm{~min}$ and the $\mathrm{pH}$ of the supernatant liquid was determined using a $\mathrm{pH}$ meter (R102895, Hanner Instruments Woonsocket). The particle size of the MCC was determined using a sieve shaker., made up of sieves ranging from $1.18 \mathrm{~mm}$ to $85 \mu \mathrm{m}$. They were arranged in descending order of size with the collector pan at the bottom. Powdered MCC of 20 $\mathrm{g}$ was placed on top of the sieve and was agitated for $5 \mathrm{~min}$. The average diameter was calculated using the formula in Eq. 3 as reported by Ansel (2005).

Average diameter $=\frac{\left(\sum(\% \text { retained }) \times(\text { mean aperture })\right)}{100}$

The true density $\left(\mathrm{D}_{\mathrm{t}}\right)$ was determined by the liquid displacement method using xylene as the immersion fluid and computed according to Eq. 4 (Ohwoavworhua et al., 2004).

$\mathrm{D}_{\mathrm{t}}=\mathrm{w} /\left[\left(\mathrm{m}_{b}+\mathrm{w}\right) \mathrm{b}\right] \times \mathrm{SG}$

Where, $\mathrm{w}$ is the weight of powder, SG is specific gravity of xylene, $\mathrm{m}_{b}$ is weight of bottle + solvent and $b$ is weight of bottle + solvent + powder. 
The static angle of repose was measured according to the fixed funnel and free standing cone method described by Ohwoavworhua and Adelakun (2010). A funnel was clamped with its tip $2 \mathrm{~cm}$ above the graph paper placed on a flat horizontal surface. The powders were carefully poured through the funnel until the apex of the cone formed just reached the tip of the funnel. The mean diameters of the base of the powder cones were determined by using a rule and measuring the width of the largest sides as observed. The tangent of the angle of repose was calculated using Eq. 5

$\operatorname{Tan} a=\frac{2 h}{D}$

Where $h$ is the height of heap of powder and $\mathrm{D}$ is the diameter of the base of heap of powder.

Fourier transform infrared (FTIR) spectrum of the MCC was analyzed and compared with that of a commercial grade MCC (Avicel PH101). The spectrum was recorded in the frequency range of $500-4000 \mathrm{~cm}^{-1}$ using an FTIR (PerkinElmer, England) at a resolution of $4 \mathrm{~cm}^{-1}$.
The morphology of the MCC samples obtained from the OPW was observed using scanning electron microscopy (SEM). This was done by placing the MCC sample in a scanning electron microscopy (Joel 6310 Instrument, Tokyo Japan) running at $10 \mathrm{kV}$ and the magnification was increased or reduced with the help of the controller interface.

\section{RESULTS AND DISCUSSION \\ Optimization of hydrolysis parameters by RSM}

ModelFitting and Analysis of Variance

The experimental results associated with the interactions between the two independent variables as well as the coded levels, actual values and observed and predicted responses are shown in table 2. Multiple regression analyses were applied on the data obtained in table 2. The regression analyses were fitted to the polynomial Eq. (2). A quadratic model was suggested by RSM and Eq. 6 was generated in terms of the actual factors

Table 2. CCD matrix for the optimization of variables and the response values of the extraction of microcellulose.

\begin{tabular}{lllllll}
\hline Run & Coded variables & \multicolumn{2}{c}{ Actual variables } & \multicolumn{2}{c}{$\begin{array}{c}\text { Response } \\
\text { MCC yield (\%) }\end{array}$} \\
\cline { 5 - 6 } & & & & & & \\
\cline { 4 - 6 } & $\mathrm{X}_{1}$ & $\mathrm{X}_{2}$ & Temperature $\left({ }^{\circ} \mathrm{C}\right)$ & Time (min) & Observed & Predicted \\
\hline 1 & 1.414 & 0 & 110 & 17.50 & 7.38 & 7.410 \\
2 & 0 & 0 & 100 & 17.50 & 14.12 & 14.50 \\
3 & 1 & -1 & 107.07 & 12.20 & 9.38 & 9.83 \\
4 & -1 & 1 & 92.93 & 22.80 & 6.38 & 6.46 \\
5 & 0 & -1.414 & 100 & 10 & 12.25 & 11.42 \\
6 & 1 & 1 & 107.07 & 22.80 & 8.23 & 7.88 \\
7 & -1 & -1 & 92.93 & 12.20 & 7.87 & 8.74 \\
8 & 0 & 0 & 100 & 17.50 & 14.30 & 14.50 \\
9 & 0 & 0 & 100 & 17.50 & 14.60 & 14.50 \\
10 & 0 & 1.414 & 100 & 25.00 & 8.13 & 8.43 \\
11 & -1.414 & 0 & 90 & 17.50 & 6.20 & 5.64 \\
12 & 0 & 0 & 100 & 17.50 & 15.00 & 14.50 \\
13 & 0 & 0 & 100 & 17.50 & 14.50 & 14.50 \\
\hline
\end{tabular}

MCC yield $=-809.61+16.00 X_{1}+2.42 X_{2}+2.30 \times 10^{-3} X_{1} X_{2}-0.080 X_{1}^{2}-0.081 X_{2}^{2}$ 
Where $X_{1}$ and $X_{2}$ are the temperature $\left({ }^{\circ} \mathrm{C}\right)$ and hydrolysis time ( $\mathrm{min}$ ), respectively. In order to determine the significance and fitness of the model, analysis of variance (ANOVA) was carried out. The results for the ANOVA for the second order response surface model are shown in table 3 . The model F-value of 77.17 with a very low probability value $(<0.0001)$ implies that the model is significant. Each term in the model was also checked for its significance.

Values of "Prob $>$ F" less than 0.0500 indicate model terms are significant. In this case, both linear model terms were significant. It was also observed that the quadratic terms of temperature $\left(X_{1}^{2}\right)$ and hydrolysis time $\left(X_{2}^{2}\right)$ were significant. The interacting term was not significant as seen in the prob value which is 0.7865 . The "Lack of Fit"
F-value of 6.56 implies that it is not significant relative to pure error. There is a $5.04 \%$ chance that "Lack of Fit" value this large could occur due to noise. Also the coefficient of variation (CV) which according to Daniel (1991) should not be greater than $10 \%$, was found to be $5.76 \%$ from the ANOVA results. The suitability of the model was also tested using the coefficient of determination $\left(\mathrm{R}^{2}\right)$ which shows the proportion of variation in the response that is attributed to the model. The $\mathrm{R}^{2}$ value was 0.9822 which is close to unity, signifying the suitability of the fitting empirical model to the actual value. The adjusted $\mathrm{R}^{2}$ value was 0.9695 which further validates the model adequacy $(\mathrm{Li}$ et al., 2011). The predicted $\mathrm{R}^{2}$ of 0.8903 was also in reasonable agreement with the adjusted $\mathrm{R}^{2}$ of 0.9695.

Table 3. Analysis of variance (ANOVA) for response surface quadratic model

\begin{tabular}{llllcrl}
\hline Source & $\begin{array}{l}\text { Sum of } \\
\text { squares }\end{array}$ & $\begin{array}{l}\text { Degree of } \\
\text { freedom }\end{array}$ & $\begin{array}{l}\text { Mean } \\
\text { Squares }\end{array}$ & F value & $\begin{array}{l}\text { Prob. value } \\
\text { Prob. }>\mathrm{F}\end{array}$ & \\
\hline Model & 144.99 & 5 & 29.00 & 77.17 & $<0.0001$ & Significant \\
$\mathrm{X}_{1}$ & 3.15 & 1 & 3.15 & 8.37 & 0.0232 & \\
$\mathrm{X}_{2}$ & 8.96 & 1 & 8.96 & 23.86 & 0.0018 & \\
$\mathrm{X}_{1} \mathrm{X}_{2}$ & 0.030 & 1 & 0.030 & 0.079 & 0.7865 & \\
$\mathrm{X}_{1}^{2}$ & 110.70 & 1 & 110.70 & 294.62 & $<0.0001$ & \\
$\mathrm{X}_{2}^{2}$ & 36.45 & 1 & 36.45 & 97.02 & $<0.0001$ & \\
Residual & 2.63 & 7 & 0.38 & & & Not significant \\
Lack of fit & 2.19 & 3 & 0.73 & 6.56 & 0.0504 & \\
Pure error & 0.44 & 4 & 0.11 & & & \\
Cor. Total & 147.62 & 12 & & & & \\
$\mathrm{CV}=5.76 \%$ & $\mathrm{R}^{2}=0.9822$ & $\mathrm{Adj}^{2}=0.9695$ & Pred $\mathrm{R}^{2}=0.8903$ & & \\
\hline
\end{tabular}

Fig. 1 shows the plot of the response predicted from the empirical model and the actual values obtained from the experiment. Most of the data points on this plot lie close to the experimental values. This was due to the large $R^{2}$ value which was almost close to unity.

\subsubsection{Influence of temperature and hydrolysis time on MCC yield}

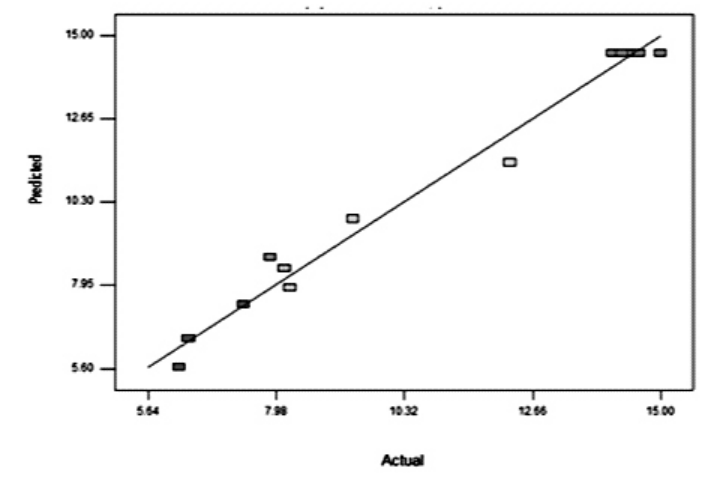

Fig. 1. Plot of predicted versus Actual yield of MCC 
Fig. 2 is a 3-D plot that shows the relationship between the dependent variable (MCC yield) and the independent variables (temperature and hydrolysis time) which was generated by the model. From the 3-D plot, it can be seen that the MCC yield initially increases with increase in the temperature and hydrolysis time. However, at temperatures above $100{ }^{\circ} \mathrm{C}$, the MCC yield begins to decrease. This decrease may be caused by complete hydrolysis or degradation of the MCC into simple soluble sugars or more soluble complex compounds as observed in the production of ethanol by acid hydrolysis method (Alemayehu, 2014). These soluble compounds are not retained on the sieve on account of their solubility in the acidic medium.

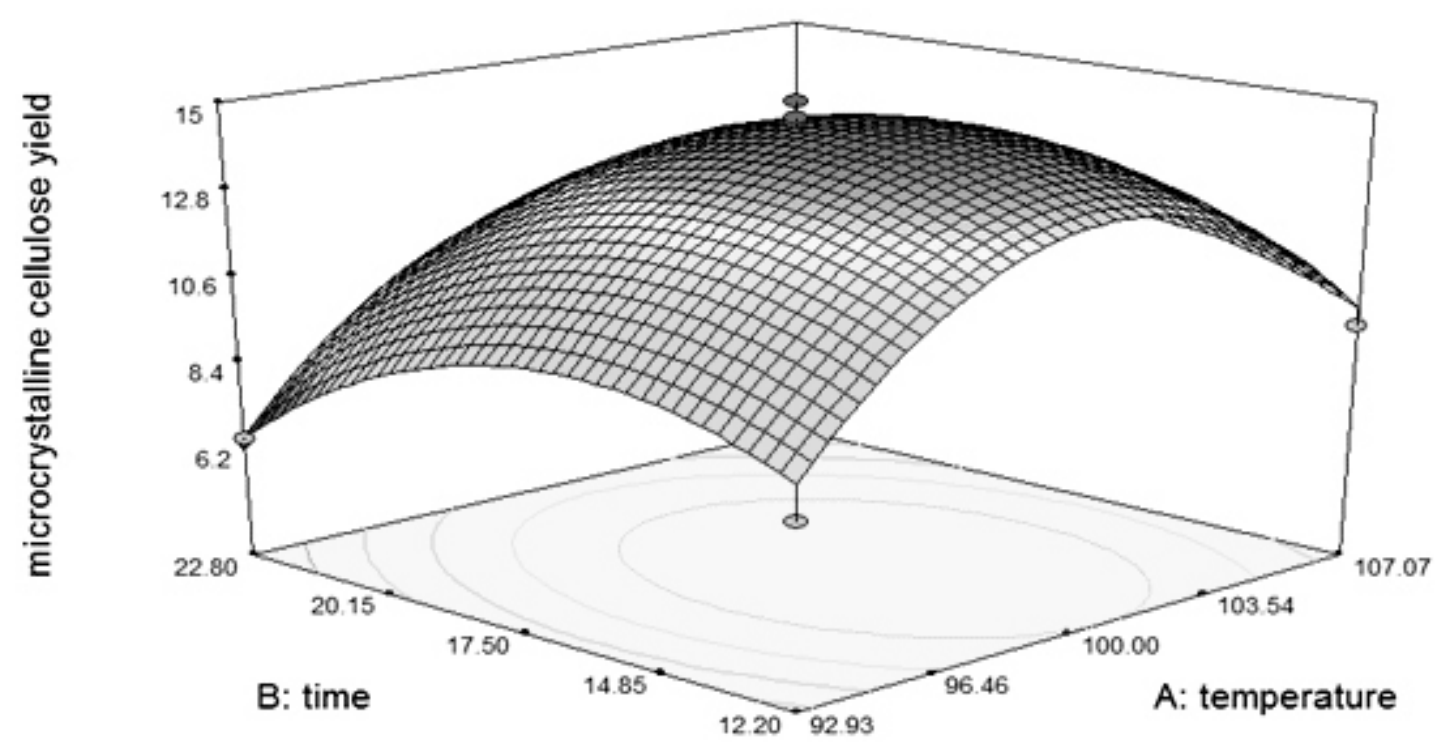

Fig.2. 3-D plot of microcrystalline cellulose yield against hydrolysis time and temperature

The individual effect of the two variables on the MCC yield was also compared. It was also observed that when the temperature was fixed at $92.93{ }^{\circ} \mathrm{C}$ and increasing the hydrolsis time, the MCC yield increases to a maximum and then decreases. On the other hand, increasing the temperature from 92.93 to $100{ }^{\circ} \mathrm{C}$ and keeping the hydrolysis time constant at 12.20 mins, there was an increase in the MCC yield from 6.2 to $12.7 \%$. It was also observed that at constant hydrolysis time, there is a decrease in the MCC yield above a $100^{\circ} \mathrm{C}$.

\section{Optimum Process Conditions}

The optimal values for the independent variables were obtained by solving the second order polynomial equation (Eq.(6)) using the software Design Expert 7.0.0. The optimum conditions were found to be at $100.53{ }^{\circ} \mathrm{C}$ and $16.28 \mathrm{~min}$. The solution to the polynomial gave an MCC yield of $14.65 \%$.

\section{Model verification}

In order to verify the suitability of the model for predicting the optimum response value, the hydrolysis experiment was carried out under these optima process conditions and the results were compared with the predicted values obtained using the model equation. These experiments were conducted twice and the mean value of the MCC yield was calculated to be $14.21 \%$.

\section{Properties of Microcrystalline Cellulose}

The results of some properties of the MCC obtained from the OPW produced at optimum process conditions were investigated and compared to that of commercially available microcrystalline cellulose (Avicel PH 101) as shown in table 4. The true density of the MCC from OPW was comparable to that of Avicel PH 101 as seen in table 4. Stamm (1964) reported that a direct correlation exists between the degree of crystallinity of cellulose and its true density when determined in a non-polar liquid. Consequently, the true density value for the MCC suggests that they may have the same degree of crystallinity with that of commercial available MCC (Avicel 
PH101).

The angle of repose of the MCC was evaluated to be $50.08^{\circ}$. The angle of repose is an indirect method of measuring the powder flowability. A high angle of repose is indicative of a poor flow (Well and Aulton, 1996). The flow properties of a powder are essential in determining the suitability of a material as a direct compression excipient.
Also from table 4, the $\mathrm{pH}$ of MCC is well within the range of commercially available MCC as stated by British pharmacopoeia (2004). The organoleptic properties of the MCC produced were good as the material was odourless, tasteless, white and granular in texture. These results indicate a high level of purity of the cellulose material.

Table 4. Properties of the MCC obtained from OPW

\begin{tabular}{lll}
\hline Property (unit) & MCC & Avicel PH 101 \\
\hline True density $(\mathrm{g} / \mathrm{ml})$ & 1.48 & 1.40 \\
Bulk density $\quad(\mathrm{g} / \mathrm{ml})$ & 0.346 & 0.415 \\
$\mathrm{pH}$ & 6.7 & $5-7.5$ \\
Angle of repose $(\varnothing)$ & 50.08 & 41.20 \\
Moisture content $(\%)$ & 6 & 7.40 \\
Organoleptic & Odourless, white, & Odourless, white, \\
& tasteless and granular & tasteless coarse powder \\
\hline
\end{tabular}

The particle size distribution of MCC powder obtained from the OPW is shown in Fig. 3. The figure represents a unimodal frequency distribution. The particle size falls in the range of
$20-85 \mu \mathrm{m}$ and can be classified as a granular powder. The calculated average diameter was found to be $56.57 \mu \mathrm{m}$.

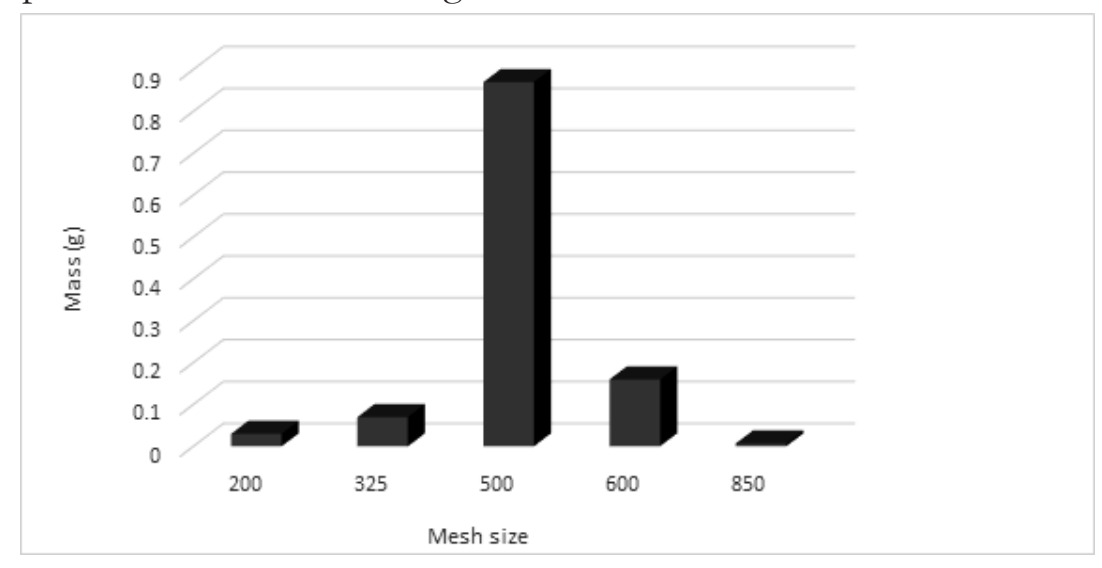

Fig.3. Particle size distribution of MCC obtained from OPW

The analysis of the MCC spectra with reference to published data by Grobe (1989), showed several typical features of the cellulose which include the characteristic intermolecular and intramolecular hydroxyl groups stretching vibration band in the spectra which occur at 3444 $\mathrm{cm}^{-1}$, the bands at 1429,1375 , and $1325 \mathrm{~cm}^{-1}$ are associated with intermolecular hydrogen bonds at the $\mathrm{C}$ group and the $\mathrm{OH}$ in plane bending vibration, respectively. The peak at the 1720.50 $\mathrm{cm}^{-1}$ is associated with the presence of the carbonyl functional groups. The band at 2918.30 $\mathrm{cm}^{-1}$ is an indication of an unsaturated carbon carbon bonding $(\mathrm{C}-\mathrm{C})$ present in the MCC. 
234 Akhabue and Osubor: Optimization of Extraction of Microcrystalline Cellulose from Orange Peel Waste

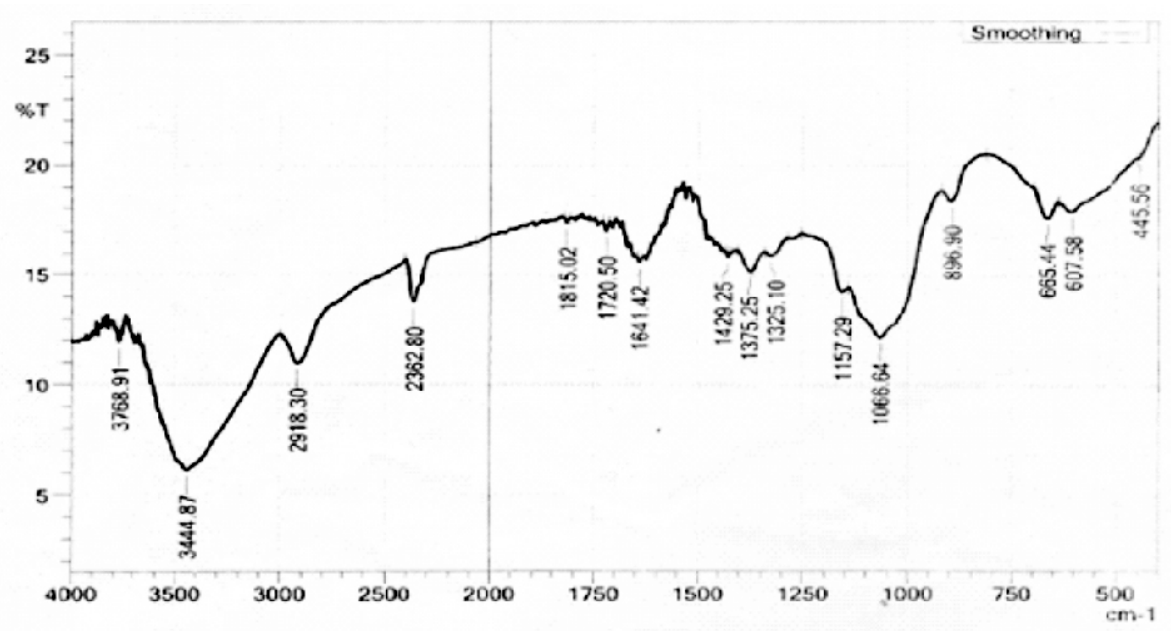

Fig. 4 FTIR spectra of MCC obtained from OPW.

Fig. $5(\mathrm{a}-\mathrm{d})$ shows the scanning electron microscopy (SEM) images of the MCC obtained from the OPW at different magnifications. As seen from figures $5 \mathrm{a}$ and $5 \mathrm{~b}$, the MCC obtained from OPW exists as irregularly shaped fibrous particles. It was observed that the MCC exist as aggregate fibres as seen from figures $5 \mathrm{c}$ and $5 \mathrm{~d}$. This is opposed to the structure of commercial

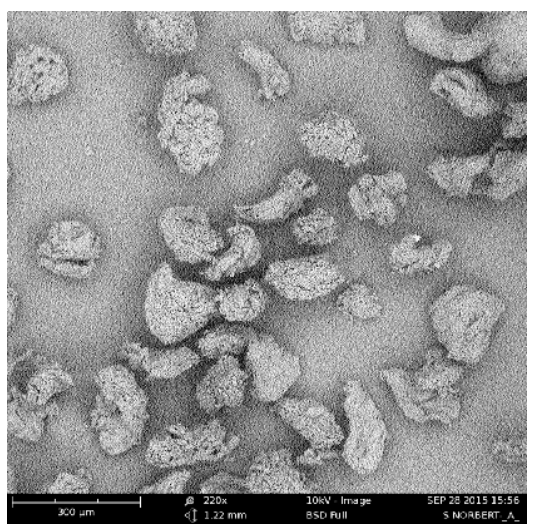

a

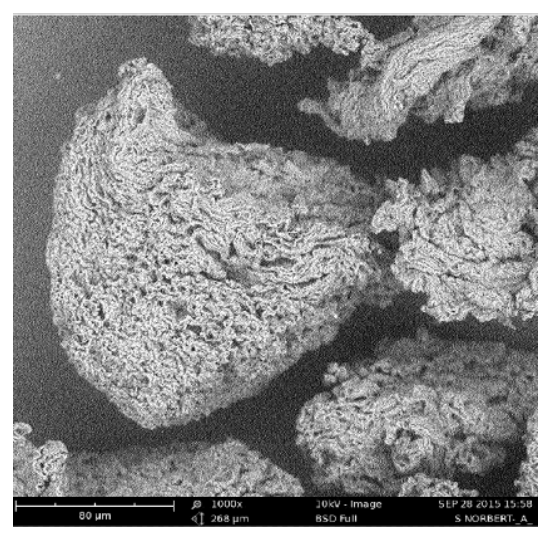

c available MCC (Avicel PH101) which exist as nonaggregated strands as described by Ohwoavworhua et al. (2004). This observation may be due to inability of the acid used in this study at the chosen constant concentration of 2.5 $\mathrm{M}$ to further breakdown the fibrous strands of the microcrystalline cellulose to much smaller sizes.

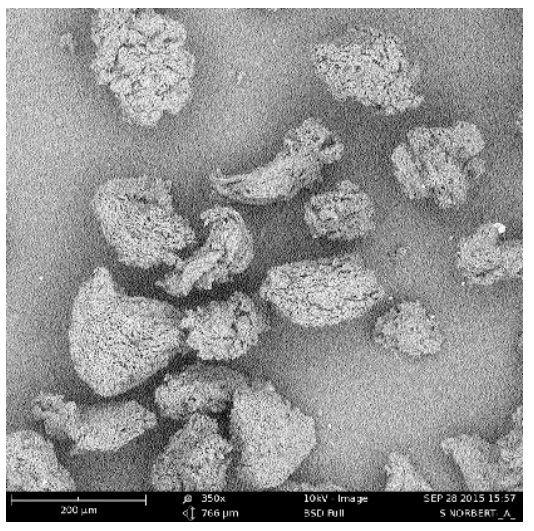

$\mathrm{b}$

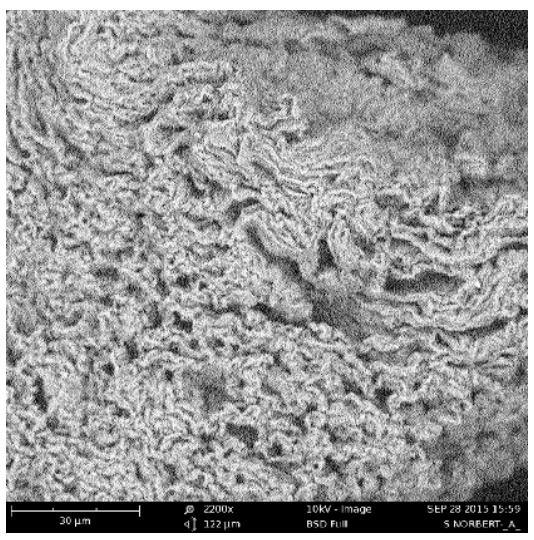

d

Fig. 5. SEM images of MCC at (a) $220 \mathrm{x}$ (b) $350 \mathrm{x}$ (c) $1000 \mathrm{x}$ (d) $2200 \mathrm{x}$ 


\section{CONCLUSION}

The extraction of microcrystalline cellulose (MCC) powder by hydrolysis of alpha cellulose obtained from orange peel waste (OPW) was optimized in this study. The two independent variables involved in the optimization were hydrolysis time and temperature. The optimum conditions for the hydrolysis of alpha cellulose were found to be at a temperature of $100.53{ }^{\circ} \mathrm{C}$ and hydrolysis time of $16.28 \mathrm{~min}$. Under these conditions, the experimental yield obtained was found to be $14.21 \%$. The powder properties indicated that the MCC obtained from the OPW and commercial grade MCC are comparable. The FTIR spectra of the MCC obtained from the OPW confirmed the presence of $\mathrm{OH}$ functional group as well as the presence of the carbon oxygen $(\mathrm{C}=\mathrm{O})$ double bond (carbonyl functional group) of the aldehyde functional group which are characteristics of cellulose. The SEM images of the MCC obtained also indicated that the MCC was composed of aggregated fibres which further validated its poor calculated flowability. The results indicated that the production of commercial grade microcrystalline cellulose from OPW is feasible.

\section{REFERENCES}

Achor, M., Oyeniyi, Y. J. and Yahaya, A. (2014). Extraction and Characterization of microcrystalline cellulose obtained from the back of the fruit of Lageriana siceraria (water gourd). Journal of Applied Pharmaceutical Sciences 4 (1): $57-60$.

Alemayehu, G. (2014) Bioethanol Production from Fruits Wastes and Factors Affecting its Fabrication. International Journal of Chemical and Natural Sciences 2(5): 132 - 140.

Ansel, C. H., Popovich, G. N. Allen, V. L. (2005) Ansel's Pharmaucetical Dosage Forms and Drugs Delivery Systems. Lippincott Williams and Wilkins, New York. p. 189

Barros, H.R., Ferreira, T.A., Genovese, M.I. (2012). "Antioxidant capacity and mineral content of pulp and peel from commercial cultivars of citrus from Brazil" Food Chem. 134: $1892-1898$.

British Pharmacopoeia (2004) Vol. I and II: Her Majesty's Stationery Office, University Press, Cambridge.

Daniel, W. W. (1991). "Biostatics: A foundation in the bealth sciences ( $5^{\text {th }}$ edition)". New York: Wiley. p.12

Evans, W. C., Trease, and Evans (1989). Pharmacognosy. "13thed. Bailliere Tindall";. p. 33977

Grobe, A. (1989). Properties of Cellulose Materials. Polymer Handbook, New York: Wiley, p. V.117-7, V144-9.

Karim, M. Z., Chowdhurry, Z. Z., Hamid, S. B. A. and Ali, M. E. (2014). Statistical Optimization for Acid Hydrolysis of Microcrystalline Cellulose and its Physiochemical Characterization by using Metal ion Catalyst. Materials 7: 6982-6999.

Klemm, Dieter, Heublein, Brigitte, Fink, HansPeter, Bohn, Andreas (2005). "Cellulose fascinating biopolymer and sustainable Raw material" Angew.chem.Int.Ed.44 (22).doi:10.1002/anie.200460587.

Li, Y., Jiang, l., Sui, X. and Wang, S (2011). "Optimization of the aqueous enzymatic extraction of pine kernel oil by response surface methodology". Procedia Engineering 15: $49-54$.

Moore, G. (1996)." Non wood fibre applications in papermaking". London: Pira International; pp. $1-4$.

Morton J. (1987). "Fruits of Warm Climates". Miami, FL, pp. 134-142

Ohwoavworhua, F. O. and Adelakun, T. A. (2010). Non - wood Fibre Production of Microcrystalline Cellulose from Sorghum caudatum: Characterization and Tableting Properties. Indian Journal of Pharmaceutical Sciences 72 (3): 295 - 301.

Ohwoavworhua, F.O., Ku nle, O. O. and Ofoefule, S.I. (2004). Extraction and characterization of microcrystalline cellulose derived from Luffa cylindrica plant. Afri. J Pharm. Res Dev. 1:1 - 6 .

Okhamafe, A.O. and Azubuike, C. P. (1994). Direct Compression Studies on Low Cost Celluloses derived from Maize Cob. J Pharm Sci Pharmacy Pract 2:26-29.

Stamm, A. F. (1964).. "Wood and Cellulose Science". New York: The Ronald Press Company; pp. 132-65.

Well, J. I. and Aulton, M.E. (1996). Preformulation. "Pharmaceutics -The Science of Dosage form". Aulton M Editor. 